\title{
Phytochemistry of the Methanolic Leaf Extract of Crotalaria lachnosema Stapf. (Fabaceae) and Acute Exposure to the Extract- induced Clinico-pathological Changes in Male Wistar Rats
}

\author{
Baba, N.D ${ }^{1^{*}}$, Njoku, C.O.I ${ }^{2}$ \\ ${ }^{1}$ Kebbi State Ministry of Animal Health, Husbandry \& Fisheries, Gidan Sara, Birnin-kebbi, Kebbi State, Nigeria \\ ${ }^{2}$ Department of Veterinary Pathology, Faculty of Veterinary Medicine, Ahmadu Bello University, Zaria, Nigeria
}

*Corresponding Author: Baba, N.D, Kebbi State Ministry of Animal Health, Husbandry \& Fisheries, Gidan Sara, Birnin-kebbi, Kebbi State, Nigeria, Email: dbabscan@gmail.com

\begin{abstract}
The study was aimed at determining the phytochemistry of the methanolic leaf extract of Crotalaria lachnosema Stapf. (Fabaceae) (MLECL) and clinico-pathological alterations that accompany acute exposure of Wistar rats to the extract. Fresh leaves and meristems of Crotalaria lachnosema Stapf. (C. lachnosema) plant were collected and dried to a constant weight in the laboratory room. The ground dried leaves of this plant were extracted in a soxhlet apparatus for 12 hours and the dried extract was used for the study. Phytochemical analysis revealed the presence of alkaloids, carbohydrates, glycosides, flavonoids, saponins, steroids, triterpenes and tannins as plant metabolites. The oral median lethal dose (LD50) of MLECLis 1300 mg per kilogram body weight. Following acute toxicity study, the rats manifested clinical signs including oral irritation, nose bleeding, arched back, restlessness, hind limb dragging and distended abdomen. Postmortem finding in rats that died of toxicity were slight congestion of the renal and hepatic congestion and hepatization of the lungs. The only microscopic lesions observed in the experimental rats were severe pulmonary and renal congestions.
\end{abstract}

Keywords: Clinico-pathological indices, Crotalaria lachnosema, LD50, and Phytochemistry.

\section{INTRODUCTION}

Toxic plants can be devastating if they are grazed upon or unintentionally incorporated into feeds or as contaminants in grains for animals and humans respectively. The genus Crotalaria, which belongs to the family Fabaceae (Leguminosae), consists of about 700 species (Polhill, 1982; Lewis et al., 2005; Adema, 2006; Mabberley, 2008) distributed throughout the tropical and subtropical regions of the world, with highest concentration in Africa. Presently, the Crotalaria species are of health importance because some of them contain pyrrolizidine alkaloids (PAs), which were reported to be cytotoxic (Srinivaset al., 2014).Both the foliage and seeds of many Crotalaria plants contain PAs (Dare et al., 2013; Maia et al., 2013;Diaz et al., 2014), thus posing potential hazard to grazing livestock. Crotalaria poisoning can either be chronic or acute (Srinivasan and Liu, 2012; Merz and Schrenk, 2016).

The Crotalaria plant occurs in Nigeria (Mattocks and Nwude, 1988), and is found in damp sites along forest margins (Burkill, 1995).
It is known by many names among various tribes in Nigeria and they include 'fara bi rana', 'Akedimwo', 'Korupo' and 'Birijibei' in Hausa, Igbo, Yoruba, and Fulani, respectively (Nuhu et al., 2009; Ibrahim et al., 2012).

In domestic animals, syndromes such as sluggishness, weakness, loss of appetite, wasting, ascites, jaundice, photosensitization and behavioural abnormalities had been observed with PAs poisoning, and were related to hepatic insufficiency (Keeler et al., 1978).Crotalaria lachnosema Stapf. was found to contain two PAs, dicrotaline and acetyl dicrotaline (Mattocks and Nwude, (1988). The folklore utilization of C. lachnosema plant in the management of liver diseases and de-worming in livestock by some communities in Zaria, Nigeria, who had no knowledge of the hazards it poses is on the increase (Nuhu et al., 2009). The plant combined with the powder of other species of Crotalaria is highly sought after for use in portion ingredients for love matters, acceptance; in written and washed Qur'anic verses in native medicine (Nuhu et al., 2009). 
In developed countries, attention had been focused on the potential hazards of low level PAs as contaminant of many food products mainly because it could lead to progressive and chronic diseases that may not present as overt hepatotoxicity (Molyneuxet al., 2011). Also, livestock poisoning, presenting primarily as liver damage had been reported worldwide following the consumption of plants containing PAs (Molyneux et al., 2011; Witabouna and Brahima, 2012).

Despite the likely dangers of grazing in $C$. lachnosema-infested lands and its folkloric medicinal use, information on the toxicological profile of this species are unavailable. The only report that Crotalaria lachnosema contain spyrrolizidine alkaloids in Nigeria were that of Mattock and Nwude (1988), previous studies (Okopido and Ogunbiyi, 1976; Nuhu et al., 2009; and Ibrahim et al., 2012) did not detect any alkaloids in the leaves of C. lachnosema Stapf. The need to document the phytochemistry and clinico-pathological changes associated with possible toxicity from the consumption of the plantin Nigeria is therefore imperative.

\section{MATERIALS AND METHODS}

\section{Crotalaria Lachnosema, Collection and Identification}

The fresh leaves and meristems of the plant species (C. lachnosema) Stapf. were collected from farmlands (Plate I) and along streams in Samaru area of Zaria. The plant was identified, confirmed and authenticated and given the voucher botanical number, 1885, at the Herbarium unit of the Department of Biological Science, Ahmadu Bello University, Zaria. The sample was air dried in the laboratory to a constant weight and then pulverized using a laboratory milling machine ( $5 \mathrm{~mm}$ sieve mesh). The powdered material was stored in a black polythene bagsat room temperature until used for extraction.

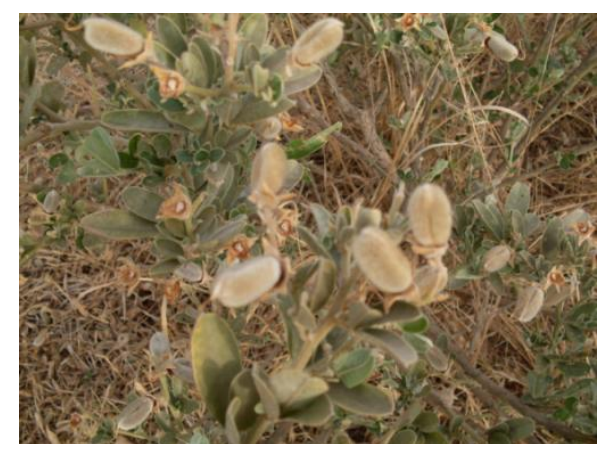

PlateI: Crotalaria lachnosema growing in farmland along Ahmadu Bello University, streams in Zaria, Nigeria

ARC Journal of Animal and Veterinary Sciences

\section{Plant Extraction}

The extraction from the plant material was conducted according to the method described by Mattocks and Nwude (1988).

\section{Phytochemical Determination}

Identification of alkaloid and other phyto constituents in the plant extract was carried out according to the method described by Trease and Evans (1983) and Nash et al.(1992)

\section{Preparation of Test Solutions}

The maximum convenient concentration (MCC) of the extract of C.lachnosema was estimated using the method described by Ibrahim et al., (1983) and Ibrahim (1984). The Stock solution of MCC was made and kept at $4{ }^{\circ} \mathrm{C}$ until required for use.

\section{Acute Toxicity Studies}

\section{Test Animals}

Fifteen 10 to 14 -week old male Wistar rats (161 $\pm 6.0 \mathrm{~g}$ ) were obtained from the animal house of the Department of Pharmacology and Toxicology, Faculty of Veterinary Medicine, Ahmadu Bello University, Zaria and used in this study. They were fed commercial grower poultry feed, maize offal and groundnut cake at a ratio of 4: 2: 1, respectively. Water was provided ad libitum.

Acute toxicity was conducted according to the method of Lorke (1983).

\section{Clinical Observations}

The rats were closely monitored during the period of exposure for signs of toxicity and death.

\section{Pathological Examination}

Immediately following the death of the MLECL-exposed rats, postmortem examination was carried out and lesions observed were recorded. Specimens from the heart, kidneys, liver, lungs, and spleen were collected and fixed in $10 \%$ buffered formalin and later processed according to standard histological techniques (Luna, 1960). The prepared histopathological slides were examined using light microscope. The lesions were recorded and photographed using a digital camera (SAMSUNG S760 Auto, $18.9 \mathrm{~mm}$ wide-angle lens, $7.2 \mathrm{mega}$ pixels, CHINA) at 400 magnification.

\section{RESULTS}

\section{Test Plant Preparation, Extraction and Yield}

The weight of the ground leaves of Crotalaria lachnosema was $800 \mathrm{~g}$, which were from a 
freshly collected samples that weighed $2269 \mathrm{~g}$. The crude methanolic soxhlet extract obtained from the ground leaves was $118.48 \mathrm{~g}$, thus, giving a percentage yield of $14.81 \%$.

\section{Phytochemical Qualitative Determination}

The phytochemical qualitative analysis revealed that the crude methanolic leaf extract of $C$. lachnosema contained alkaloids (Mayer's and Dragendorff's tests), carbohydrates (Molisch's test), cardiac glycosides (Kella-killiani test), flavonoids (Sodium hydroxide test), saponins (Frothing test), steroids and triterpenes (Lieberman-Burchards test), and tannins (Ferric chloride test). The pyrrolizidine alkaloid obtained was $360 \mathrm{mg}(0.09 \%)$ from $400 \mathrm{~g}$ of ground dried leaves of Crotalaria lachnosema.

\section{Acute Toxicity}

In phase I of the study, no death was observed following exposure of the rats to the extract at $10 \mathrm{mg} / \mathrm{kg}, \quad 100 \mathrm{mg} / \mathrm{kg}$, and $1000 \mathrm{mg} / \mathrm{kg}$ body weight. In the phase II, all the dose levels of the extract, $1600 \mathrm{mg}, 2900 \mathrm{mg}$ and $5000 \mathrm{mg} / \mathrm{kg}$ body weight, caused death of the 3 rats within the first 24-hour observation period. A repeat of the phase II at dose levels of $1000 \mathrm{mg}, 1200 \mathrm{mg}$, and $1400 \mathrm{mg} / \mathrm{kg}$ was done, only the $1400 \mathrm{mg} / \mathrm{kg}$ dose level caused death of the rat. Thus, an $\mathrm{LD}_{50}$ of $1300 \mathrm{mg} / \mathrm{kg}$ was arrived at for MLECL.

\section{Clinical Signs of Acute Toxicity}

The clinical signs observed in the rats in this acute phase of the study were oral irritation, nose bleeding, restlessness, arched-back, hyperpnoea, depression/weakness, hind limbs dragging, bloat (Plate II) and death.

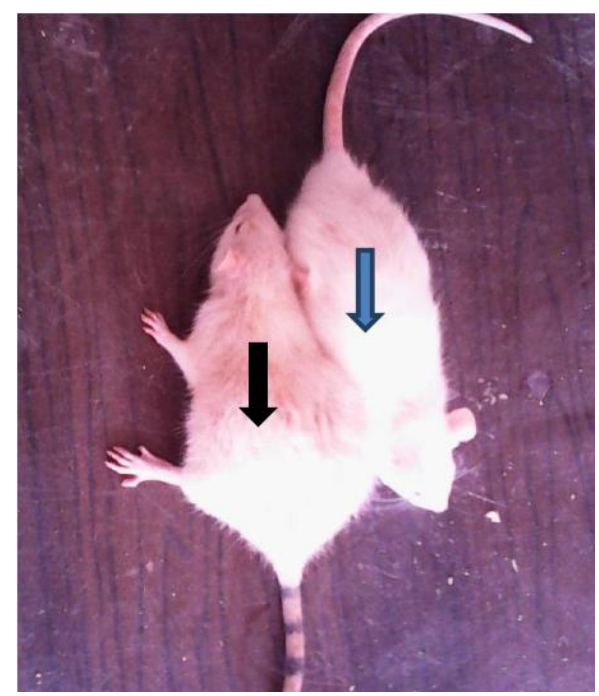

Plate II: Exposure to the MLECL in rats caused distended abdomen (black arrow) compared with the normal rat (blue arrow).

\section{Gross Pathological Findings from Acute} Toxicity of MLECL

The gross post-mortem lesions observed in the dead rats during this study were slight congestion of the liver, kidneys and red hepatization of the lungs.

\section{Histopathological Findings in the MLECL- Exposed Rats}

Theacute exposure of the rats to MLECL resulted in severe congestion of the kidneys (Plate III) and lungs (Plate V) of the rats. There were noobservable histological lesions in the liver, heart and spleen of the control (Unexposed) rats.

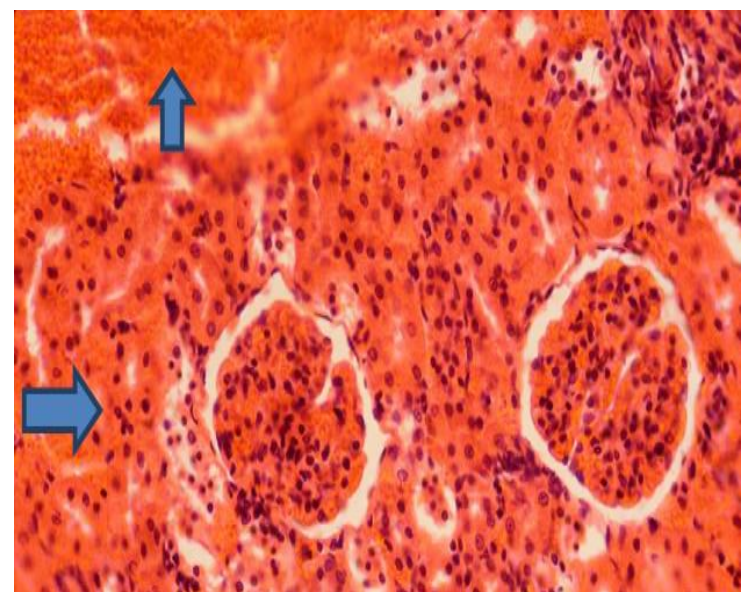

Plate III: Photomicrograph of a section of kidney from rats exposed to MLECL showing severe congestion of the kidney (blue arrows), ( $H \& E x$ 400).

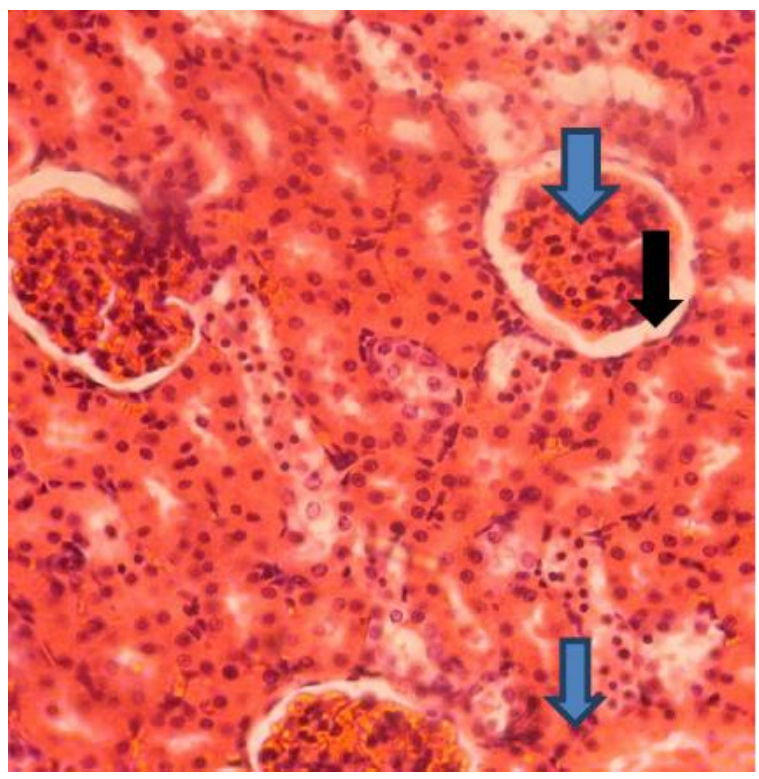

Plate IV: Photomicrograph of a section of kidney from an unexposed rat showing the glomerulus (blue arrow), intact Bowman's capsule and clear bowman's space (black arrow) (H\& Ex 400). 


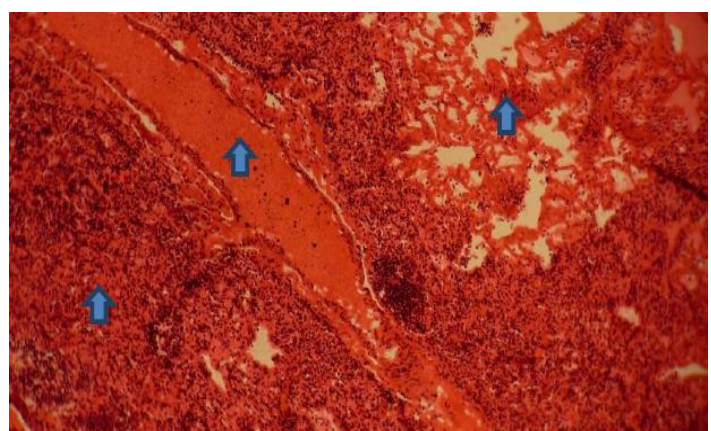

Plate V: Photomicrograph of a section of lung (Acute toxicity/LD $D_{50}$ ) from extract exposed rat showing severe congestion of the entire lung (blue arrow), ( $H \& E x 100)$.

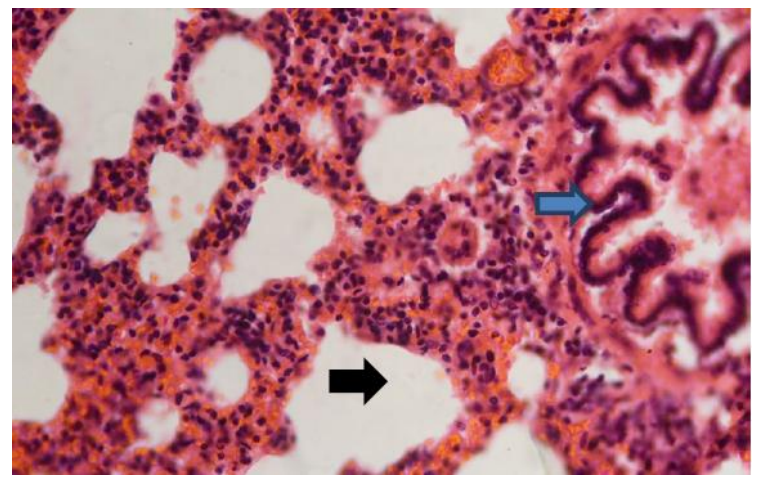

Plate VI: Photomicrograph of a section of lung from unexposed showing the intact alveolus (black arrow), and intact bronchiole (blue arrow), ( $H \& E x 400)$.

\section{DISCUSSION}

In the present study, the oral $\mathrm{LD}_{50}$ of 1300 $\mathrm{mg} / \mathrm{kg}$ obtained indicate that the methanolic leaf extract of C. lachnosema Stapf. was slightly toxic to rodents based on the reported classifications of the severity of the oral $\mathrm{LD}_{50}$ (Matsumura and Mizushima, 1975; Corbett et al., 1984; OECD, 2008). The classification of the $\mathrm{LD}_{50}$ in this study notwithstanding, the finding that the kidneys and the lungs were also severely congested suggests that the leaves of Crotalaria lachnosema could pose potential hazards to animals grazing in lands infested with this plant or endanger humans who make folkloric use of it in the management of different health ailments.

The phytochemical qualitative analysis revealed that the crude methanolic leaf extract of $C$. lachnosema contained alkaloids (Mayer's and Dragendorff's tests), carbohydrates (Molisch's test), cardiac glycosides (Kella-killiani test), flavonoids (Sodium hydroxide test), saponins (Frothing test), steroids and triterpenes (Lieberman-Burchards test), and tannins (Ferric chloride test). The crystalline alkaloid obtained in this study was quantified at $360 \mathrm{mg}(0.09 \%)$ from $400 \mathrm{~g}$ dried ground leaves of Crotalaria lachnosema using the method described by Mattocks and Nwude, 1988. Phytotoxicological studies have always been considered vital prior to plant usage as foods, cosmetics and medicine indiscriminately without recourse to potential side effects, which could vary from mild to moderate or severe and life threatening (WHO, 2000).

\section{CONCLUSION}

In conclusion, the present toxicity studies have provided insight on the toxicological status of the leaves of the plant, C. lachnosema Stapf. found in Nigeria. For the first time we have been able to show that; the oral $\mathrm{LD}_{50}$ of 1300 $\mathrm{mg} / \mathrm{kg}$ obtained indicate that the methanolic leaf extract of C. lachnosema Stapf. was slightly toxic to rodents. The clinical signs observed in the acute phase of the study were oral irritation, nose bleeding, restlessness, arched-back, hyperpnoea, depression/weakness, hind limbs dragging, bloat and death, as well as congested kidneys and lungs. The phytochemical qualitative analysis revealed that the crystalline alkaloid obtained in this study was quantified at $360 \mathrm{mg}(0.09 \%)$ from $400 \mathrm{~g}$ dried ground leaves of Crotalaria lachnosema using the method described by Mattocks and Nwude, 1988.

\section{RECOMMENDATIONS}

Herbal medicinal products containing toxic pyrrolizidine alkaloids (even in very low amounts) should be regarded as very hazardous. Extensive and intensive studies on the toxicity profiles of plants containing pyrrolizidine alkaloids in Nigeria and elsewhere in the world should be sustained.

\section{REFERENCES}

[1] Adema F (2006). Notes on Malaysian Fabaceae (Leguminosae -Papilionoideae): The Genus Crotalaria. Blumea, 51: 309-332.

[2] Corbett AD, Gillan MC, Kosterlitz HW, McKnight AT, Paterson SJ \& Robson LE (1984). Selectivities of opioid peptide analogues as agonists and antagonists at the $\delta$-receptor. British journal of pharmacology, 83(1): 271-279.

[3] Dare TA, Nwude N, Rekwot PI, Mamman M \& Omontese BO (2013). Screening of some Nigerian plants for pyrrolizidine alkaloids. Scientific Journal of Animal Science, 2(6): 138-143.

[4] Diaz GJ, Almeida LX \& Gardner DR (2014). Effects of dietary Crotalaria pallida seeds on the health and performance of laying hens and 
evaluation of residues in eggs. Research in veterinary science, 97(2): 297-303.

[5] Ibrahim AJ, Makinde O \& Ibekwe NN (2012). Pharmacognostic, Physicochemical standardization and Phytochemical Analysis of leaves of cultivated Crotalaria lachnosema stapf. Journal of Applied Pharmaceutical Sciences, 2(9): $067-070$.

[6] Ibrahim M.A, Nwude N, Ogunsusi RA \& Aliu YO (1983). Screening of some plants used as anthelmintic in African traditional Veterinary and human medicine for activity against Nippostrongylus braziliensis in rats. Paper presentation at the $5^{\text {th }}$ International symposium on Medicinal plants, University of Ife, Ile-Ife Nigeria July $13-15^{\text {th }}, 1983$.

[7] Ibrahim MA (1984). Evaluation of the activities of some West African tradictional anthelmintic herbs against nippostrogylus braziliensis in rats. M.Sc. Thesis, A.B.U. Zaria, Pp. 116.

[8] Keeler RF, Van Kampen KR \& James LF (1978)(editions). Effects of poisonous plants on livestock. New York: Academic Press.ro

[9] Lewis G, Schrire B, Mackinderand B \& Lock M (2005) (editions.). Legumes of the World. Royal Botanic Gardens, Kew, U.K. Pp 1-577.

[10] Lorke D (1983). A new approach to practical acute toxicity testing. Archives of toxicology, 54(4): 275-287.

[11] Luna LG (1960). In Manual of Histologic Staining of the Armed Forces Institute of Pathology, 94-95.

[12] Mabberley DJ (2008). Mabberley's Plant-Book: A portable dictionary of plants, their classification and uses. Third Edition. Cambridge University Press, Cambridge. viixviii, 1-1021.

[13] Maia LA, de Lucena RB, Nobre VMDT, Dantas AF, Colegate SM \& Riet-Correa F (2013). Natural and experimental poisoning of goats with the pyrrolizidine alkaloid-producing plant Crotalaria retusa L. Journal of Veterinary Diagnostic Investigation, 25(5): 592-595.

[14] Matsumura N \& Mizushima Y (1975). Leucocyte movement and colchicine treatment in Behçet's disease. The Lancet, 306(7939): 813.

[15] Mattocks AR \&Nwude N (1988). Pyrrolizidine alkaloids from Crotalaria lachnosema and
Crotalaria naragutensis. Phytochemisty, 27 (10): 3289 - 3291.

[16] Merz KH, \& Schrenk D (2016). Interim Relative Potency Factors for the Toxicological Risk Assessment of Pyrrolizidine Alkaloids in Food and Herbal Medicines. Toxicology letters.

[17] Molyneux RJ, Gardner DL, Colegate SM \& Edgar JA (2011). Pyrrolizidine alkaloid toxicity in livestock: a paradigm for human poisoning? Food Additives \& Contaminants: Part A, 28 (3): 293 - 307.

[18] Nash RJ, Beaumont J, Veitch NC, Reynolds T, Benner J, HughesCNG, Dring JV, Bennett RN \& Dellar JE (1992). Phenylethylamine and piperidine alkaloids in Aloe species. Planta Medica, 58(1): 84-87.

[19] Nuhu H, Abdulrrahman EM \& Shok M (2009). Ethnobotanical studies on Crotalaria species found in Zaria, Northern Nigeria. Nigeria Journal of Pharmaceutical Sciences, 8: 46 - 53.

[20] OECD (2008). Test No. 407: Repeated Dose 28-day Oral Toxicity Study in Rodents, in OECD Guidelines for the Testing of Chemicals, Section 4, (OECD Publishing;). 10.1787/ 9789264070684-en.

[21] Srinivas N, Sandeep KS, Anusha Y\& Devendra BN (2014). In Vitro Cytotoxic Evaluation and Detoxification of Monocrotaline (Mct) Alkaloid: An In Silico Approach. Int. Inv. J. Biochem. Bioinform, 2(3): 20-29.

[22] Srinivasan P \& Liu MY (2012). Comparative Potential Therapeutic Effect of Sesame Oil and Peanut Oil against Acute Monocrotaline (Crotalaria) Poisoning in a Rat Model. Journal of Veterinary Internal Medicine, 26(3): 491499.

[23] Trease GE \& Evans WC (1983). Drugs of Biological Origin. In: Pharmacognosy $12^{\text {th }}$ ed. United Kingdom: Balliere Tindall. 309-540.

[24] Witabouna MK \& Brahima K (2012). Qualitative Analysis of Pyrrolizidine Alkaloids from 11 Asteraceae and Boraginaceae Used in Traditional Medicine in Cote d'Ivoire. Research Journal of Phytochemistry, 6: 75-83.

[25] World Health Organization (2000). General Guidelines for Methodologies on Research and Evaluation of Traditional Medicine. Geneva: WHO Press, World Health Organization.

Citation: Baba, N.D, Njoku, C.O.I. Phytochemistry of the Methanolic Leaf Extract of Crotalaria lachnosema Stapf. (Fabaceae) and Acute Exposure to the Extract-induced Clinico-pathological Changes in Male Wistar Rats. ARC Journal of Animal and Veterinary Sciences. 2017; 3(3):24-28. doi: dx.doi.org/ 10.20431/24552518.0303004.

Copyright: (C) 2017 Authors. This is an open-access article distributed under the terms of the Creative Commons Attribution License, which permits unrestricted use, distribution, and reproduction in any medium, provided the original author and source are credited. 